\title{
Which Factors Affect Most Buyers' Choices Between Fuel and Electric Vehicles?
}

\author{
Rafayela Gyulbudaghyan ${ }^{1}$, Nurul Zarirah Nizam ${ }^{2,3}$ \& Yasuo Hoshino ${ }^{2,4}$ \\ 1 London School of Commerce, London, United Kingdom \\ 2 Graduate School of Business Administration, Aichi University, Nagoya, Japan \\ 3 Faculty of Technology Management \& Technopreneurship, University of Technical Malaysia, Melaka, \\ Malaysia \\ 4 Institute of Policy and Planning Sciences, University of Tsukuba, Tsukuba, Japan \\ Correspondence: Nurul Zarirah Nizam, Graduate School of Business Administration, Aichi University, Nagoya, \\ Japan. Tel: 81-90-4261-4444. E-mail: zarirah@utem.edu.my
}

Received: May 19, 2014 Accepted: June 1, 2014 Online Published: September 28, 2014

doi:10.5539/ijms.v6n5p73 URL: http://dx.doi.org/10.5539/ijms.v6n5p73

\begin{abstract}
The aim of the given research is to find out the factors besides of those based on price, which are affecting people's choices when acquiring a new greener vehicle. At first sight it might seem that the answers could be quite obvious: we can always argue that the market of electric vehicles is very weak, regarding its reliability, the inconveniences with charging the batteries, the price, the aftermarket, etc. The figures for recent years show that the level of carbon emissions has decreased due to the sanctions undertaken by the government, such as congestion charges especially for the central zones of London. The sampling for this research was randomly chosen people in the streets and shops in Central London. As a result of the survey, data analysis reveals that customers are mostly affected by the design of electric vehicles. Surprisingly enough price as a factor is only at the third place of importance for most of the respondents. As the analysis of open questions suggests the majority is positive for the future of electric vehicles, but they are rather concerned for technical issues such as life of batteries, charging points around London and surrounding areas.
\end{abstract}

Keywords: global automotive trends, electric vehicles, social responsibility, technological development, consumer behaviour, green issues, ecological footprint

\section{Introduction}

\subsection{The Importance of Automotive Industry}

Automotive industry has undergone a number of changes since the moment of its emergence becoming a vital part of not only being means of transportation but also a source for employment, a source for supplier business development and an issue of environmental well-being. Automotive industry nowadays has an important role for the UK economy as related to turnovers and values added. Over 40 companies are based in the United Kingdom. They produce over one million cars and commercial vehicles. 180,000 UK jobs are supplied by the automotive manufacturing and 640,000 UK jobs rely on automotive supply, retail and servicing (Society of Motor Manufacturers and Traders, 2009). The aim of the given research is to find out the factors besides of those based on price, which are affecting people's choices when acquiring a new vehicle depending on either it being petrol, diesel, hybrid or an electric one. At first sight it might seem that the answers could be quite obvious: we can always argue that the market of electric vehicles is very weak, regarding its reliability, the inconveniences with charging the batteries, the price, the aftermarket, etc. From the point of view of ecology these vehicles are harmless, but some sceptics might again argue that even if these cars do not pollute the environment, still there is a need of energy to charge the batteries, and that energy is being created by polluting the same or some other area. Nonetheless, the figures for recent years show that the level of carbon emissions has decreased, due to the sanctions undertaken by the Government such as congestion charges especially for the central zones of London (Hailes, 2007:181). Partially it might also be the result of people's awareness and concern to some extent of the environmental issues existing nowadays, thus threatening the future generations and the planet's well-being. 


\subsection{Current Trends of Automotive Industry}

Comparing Europe to the rest of the world, the difference between cultures and the level of development and understanding of the urging issues are also important to consider for customer behaviour description. Nevertheless the main focus will be remaining on the UK's customers, main target for the research is London, while figuring out how well people are concerned with their own carbon footprint, how much they are ready to spend on a vehicle, if the design is important for the acquisition of a lower carbon car, are the governmental subsidies enough for the potential customers to enjoy and what else should be done to improve the current situation, as well as what are the current trends.

1) To define the problems and trends of the present automotive industry;

2) To critically review the information and what is the background for triggers affecting consumers' choices

3) Collect data and analyse them in order to see if the research proves the primary hypothesis;

4) Define the factors besides those of price which affect the consumers during the process of making purchase decisions and give further recommendations.

It is scientifically proven that emotions are a way to understand human behaviour. Emotions get pictures from our daily lives, and then save them in our memory, and on a particular moment recall them from there (Hansen \& Christensen, 2007). Consumers are led by their emotions, but when it comes to such factors as price, urgency, ethics, etc. do they always follow their emotions or are they controlled more by logical assumptions? In case of acquiring a vehicle it is more logical that the first criteria that comes on top is the price, even though the pictures from a commercial are so captivating and assuring. Thus the price is a limitation number one for a consumer who, let's assume, wants to live ethically and is concerned with environmental issues. The other factors will reveal themselves during the research.

Global Automotive Trends: Globally automotive industry is mostly subject to a range of outer political, economic, social as well as regulatory pressures, such as consumer emotions, environmental and safety regulations, technological development, exchange rates, taxation, etc. Although both the governments and the industry itself may have a limited influence over the above-mentioned factors, they and more others can drastically affect the industry. There is a risk at present linked to the existing difficulties both for industry and governments to concentrate on. On the other hand there has always been a demand for a car, and thus there will always be a demand for the industry (New Automotive Innovation and Growth Team, NAIGT, 2009). According to Mayor and Greater London Authority (2009) the answer to the question "why electric vehicles?" is described as follows: electric vehicles have an effect of reducing the emissions of $\mathrm{CO}_{2}, \mathrm{NOx}$, etc. as compared to the internal combustion engine vehicles. The strategy plan encompasses three key areas: infrastructure, vehicles and incentives (including marketing and communications). In 2013, there was a plan continued phased installation of 1300 public charge points on residential streets and off-street locations, such as supermarkets, public car parks and at shopping and leisure centres in the centre of London. (https://www.sourcelondon.net/source-london).

Technological Development: Lithium ion battery technologies are developing really fast, the evidence of that is the new method of manufacturing ion-lithium batteries, which can be charged in just seconds. The trick is in the transportation of ions through the material. Thus the researchers have come to a conclusion that another material such as lithium iron phosphate actually does not lose the capacity to charge over the time, henceforth the use of a new material means that new generation of chargeable batteries are phenomenally smaller and it will take just seconds to charge them (http://news.bbc.co.uk/1/hi/7938001.stm).

Social Responsibility: Many companies start thinking deeper thus aiming at finding philosophy behind the business they have undertaken. As related to vehicle manufacturers, much of the guilt for polluting the air is placed on them. Thus when the players for the market start understanding the problems and realizing the fact that they can actually get a step ahead and present themselves from a better, more ethical angle, they find better solutions through the concept of corporate social responsibility. One of the widespread approaches is that no business can survive if it does not act in accordance with its environment. Another definition can be "a combination of the company's actions and the norms which are set by the stakeholders" (Nussbaum, 2008).

Consumer Behaviour: Consumer behaviour as a concept is rather wide and abstract. Consumer behaviour encompasses the processes of individuals or groups selecting, purchasing, using or disposing products, services, ideas or experiences to satisfy their needs and desires (Solomon et al., 2006:27). Another definition that consumer behaviour reflects the totality of consumer's decisions with respect to the acquisition, consumption and disposition of goods, services, activities, experiences, people and ideas by humans over time (Hoyer and Macinnis, 2010). 
Green Issues: Being an ethical consumer will consequently mean supporting the local organic products as well as accepting the responsibility to take care of the environment. Thus in the process of making ethical choices in acquiring products the choices will be falling in 5 categories: 1) no brainer, where the ethical issues are clear, they do not require much effort, for example using energy-efficient light bulbs - they cost a little more, but on the other hand they save more; 2) must-do, which means that the ethical issues are very clear regardless the cost and even the effort, such as not buying products which are originally from dictatorial countries, which kills people and is against democracy; 3) worth doing, here the ethical imperative is not so strong, the issues are again clear. For example fair trade goods give the growers from poorer countries better deals, but these products cost usually more and you may find yourself dealing with a bit more effort finding them on shelves; 4) calculation, this point usually depends on a number of factors, and they need to be balanced. For example an individual as a consumer might be faced with a dilemma when acquiring an eco-friendly vehicle; on the one hand it consumes less petrol, but on the other hand the total energy and resource usage over its lifetime might not come into balance with the idea. The main issues connected with this type of decision are that some of the figures may be known whereas the others might be missing; 5) value-judgement, such situations mostly refer to people's own values as choosing the prevailing ethical issue. For example accepting or despising the life-saving drug considering the fact it has been tested on animals mostly depends on the limits of beliefs of the individual. Milder aspect is for products of beauty, an ordinary pain-killer, etc. (MacBride, 2009:4). Thus, the express the decision-making process it can be drawn as a figure presented below:

Ecological Footprint: "Road transport is responsible for the quarter of the total $\mathrm{CO}_{2}$ emissions in the UK, and around $15 \%$ of the total worldwide. In 1980, the 12 million or so cars and taxis on Britain's roads travelled 10 billion miles a year; by 2004, 24 million vehicles were traveling 240 billion miles a year; by 2010 there are likely to be nearly 35 million cars and taxis in the UK. And this does not include trucks and lorries" (MacBride, 2009:80). Transport fuels are the supply for the one third of total energy use in the UK by (Scurlock, 2010:49). The British government's Renewable Transport Fuels Obligation is substituting conventional biofuels mixed with a proportion of fuels which is derived from agricultural crops: oil seed rape, palm oil, wheat and sugar. Thus biomass fuels are those that are made of plant matter, whereas most transport fuels are derived from fossil fuel such as coal and natural gas.

According to data (Goodall, 2009:15) private cars carry the responsibility for about $12 \%$ of the UK's green-house emissions. Commercial vehicles, such as vans and lorries add up more $8 \%$ to the number. The European Commission also reported that the $\mathrm{CO}_{2}$ levels form new cars all over the Europe have decreased by 5\% as opposed to last year. Climate Action Commissioner Connie Hedegaard said: "Reducing road transport $\mathrm{CO}_{2}$ emissions remains a major challenge for the future. The latest data shows however the car industry is on track to achieve the 2015 target, keeping the EU industry at the front-edge of competitiveness." (www.smmt.co.uk).

\subsection{Hypothesis Development}

Hypothesis for the given research is that besides of the price factors for the electric vehicles, is another one, which comes logically if we think that there were no other means of transportation, meaning no other types of vehicles, then the consumers will be left with no other choice but going for electric ones. As we have seen from the literature review the government's sanctions such as congestion charges on the $\mathrm{CO}_{2}$ emitting vehicles as well as subsidies and grants for electrics, hybrids and zero emission ( 0 emission alternative fuelled) vehicles, there are still factors remaining there to affect people. Thus the focus here remains on finding the ways, methods and techniques to generate data and interpret them.

\section{Method}

\subsection{Sampling Plan}

As regarding the sampling for the questionnaires, the number of respondents turned to be 39 . People in different places were asked to fill the questionnaires in. Obviously by-passers in the street did not have much time to stand around and do the researcher a favour. So the strategy for finding respondents needed to be changed. People in Starbucks and McDonalds turned out to be better respondents ready to assist in the research. Since the requirement for a respondent was just to be a driver, most of the respondents were of young age due to the places where the questionnaires were handed over. This is another limitation that there is no even number for the age groups. 


\subsection{Conducting Interview}

There were no phone interviews made, and they were supposed to be in-person and the type of the interview was supposed to be structured one with ready questions. The interviewee was supposed to be the person inside the industry who deals with electric vehicle issues, but the limitation was that the person could not be available due to the fact that she was away from the country. The interview was conducted at the $\mathrm{ECO}_{2}$ Transport show which was held on 16-18th November 2010.

\section{Results}

\subsection{Interview Analysis}

This unstructured interview was held with the participants of the $\mathrm{ECO}_{2}$ Transport Exhibition Show at the 16-18 of November, 2010. One of the colleagues of the "Surveyor" Magazine mentioned that the problems are really important for future. If we do not stop the pollution now, it will be much more difficult for the future generations to cope with the greenhouse effects. In addition, there are campaigns that encourage people to save more energy, to save on the roads, on their own cars, etc, but the issues are not well communicated to ordinary people and that the knowledge is not of a high level as compared to many Scandinavian countries. There is a trend where people become more concerned and more thoughtful about greener issues.

Another interviewee from Carbon Voyage Ltd. that delivered a speech during the seminar on "Behaviour and Technology in Sustainable Travel" mentioned the human behaviour and its importance towards sustainable transport strategies. It is worth noting that Carbon Voyage exists to move people and things around in the most efficient, effective and environmentally-friendly way possile. The interviewee was rather concerned with reducing costs on roads while travelling. The behaviour is changing in London. So if someone could share a car with their neighbour or a colleague, the easier it would be to reduce both the costs and the carbon emissions. Some of the organisations are coming to force people to more sustainable travels. For example if there is a limited days driving in the crowded city, charging higher toll, and less space for parking, people would consider travelling less by their own car. The interviews also showed that people are not well-informed and to a lesser degree concerned with issues.

\subsection{Survey Findings}

Table 1. Age group percentage

\begin{tabular}{lll}
\hline Age groups & Number of Respondents & Percentage \\
\hline $18-25$ & 9 & $23.08 \%$ \\
$26-35$ & 21 & $53.85 \%$ \\
$36-45$ & 3 & $7.70 \%$ \\
$56-55$ & 3 & $7.69 \%$ \\
$56-65$ & 3 & $7.69 \%$ \\
\hline
\end{tabular}

Table 1 shows age group percentage of the respondents. The majority is 21 people who belong to the group of 26-35 years old. The 18-25 age groups has 9 people in it, and the other groups were 36-45, 46-55 and 56-65 which have 3 people respectively.

Table 2. Figures turned into percentages

\begin{tabular}{|c|c|c|c|c|c|}
\hline Marks of Importance & 1 & 2 & 3 & 4 & 5 \\
\hline Design & & & $7.69 \%$ & $61.50 \%$ & $30.70 \%$ \\
\hline Type of vehicle & $7.69 \%$ & & $7.69 \%$ & $46.15 \%$ & $38.50 \%$ \\
\hline Colour & & $30.70 \%$ & $23.08 \%$ & $23.08 \%$ & $23.08 \%$ \\
\hline Brand & & & $38.50 \%$ & $30.70 \%$ & $30.70 \%$ \\
\hline Fuel efficiency & & & $15.38 \%$ & $53.85 \%$ & $30.77 \%$ \\
\hline Size & & & $15.38 \%$ & $53.85 \%$ & $30.70 \%$ \\
\hline Environmental impact & & $23.08 \%$ & $15.38 \%$ & $53.85 \%$ & $7.69 \%$ \\
\hline
\end{tabular}

Question 10. was designed to find out factors which could be important to the customer when purchasing a car. The factors also needed to be evaluated according to their importance. The scale for the evaluation starts from 1 comprising the least importance and 5 showing the highest significance during the process of purchase decision 
making. This finding shows that people are concerned with the type of the vehicle. Although it is again of not huge significance to the majority. The last factor in the questionnaire was the environmental impact. 21 people have chosen mark ' 4 ', nine people mark ' 2 ', six people mark ' 3 ' and only three people considered the environmental impact the most esssential choosing mark ' 5 '. Again the level is high for mark ' 4 ', which proves that people are pretty much worried about the ecology. Though quite prominent is to also note that 6 people are not really bothered about it. To assume that $15.38 \%$ of the respondents do not have much concern for ecological issues when making a purchase is not a very happy thought. Although $53.85 \%$ of the respondents are pretty concerned with the issue which gives quite a positive hope for the future.

Table 3. Criteria for acquiring electric vehicle (percentages)

\begin{tabular}{ll}
\hline Cheaper than alternatives & $51.28 \%$ \\
No road fund license & $33.33 \%$ \\
Zero emissions & $12.82 \%$ \\
They were quiet to drive & $17.94 \%$ \\
They had a better design & $56.41 \%$ \\
All other cars are banned & $58.97 \%$ \\
More reliable & $46.16 \%$ \\
Others & $0 \%$ \\
\hline
\end{tabular}

Question 14. in the questionnaire reflects on the criteria of purchasing an electric vehicle. Being more concise it actually suggests variants of criteria for the customers to choose from. It is worth mentioning that the respondents are encouraged to tick more than just one criteria if it is applicable. 'You would acquire an electric vehicle if:' and the answers are shown in Table 3 for the percentages respectively.

\section{Discussion}

The top three answers to Question 14 are 'all the other cars are banned' with the highest number of "votes" 23 (which is equal to $58.97 \%$ ), the second place is the answer 'they had a better design' with 22 votes $(56.41 \%$ ) and the third place is saved for answer 'they were cheaper than petrol and/or diesel alternatives' with 20 votes $(51.28 \%)$. As the primary hypothesis was suggesting, the results of this question are proving the truthfulness of it This means that if people did not have any other alternative vehicles to drive, then the choice is basically for the electric ones. This means if the government adopted any sanctions against all other vehicles then people would definitely buy and moreover drive those cars. The second highest scored criterium is the design of electric vehicles. Obviously people are more concerned with the external and internal looks of the car they are driving. So this is a good point for the producers of electric vehicles to pay attention to. Surprisingly enough the prices of electric vehicles were not on the first place. This means that either the respondents did not have any financial difficulties in acquiring a new vehicle or the price is not an important factor. Most of the respondents are ready to spend from $£ 5,000-£ 20,000$ on a new vehicle.

Questions 12,13,15 and 16 were open questions where the respondents were free to express their views on the issues.

Question 12 was asking the respondents what they know about the Government's measures as related to electric (alternative) vehicles. Most of the respondents had no idea about any kind of measures. It is quite surprising that only 4 or five people mentioned the compensation schemes and/or exemption from the congestion charges. One of the respondent's also stated that electric vehicles are exempt from parking fees. The other mentioned about private companies that encourage their employees buying electric vehicles since they are concerned about the environmental issues, however could not mention any of the measures undertaken by the government.

Question 13 was asking about the repondents' opinions on the idea of electric vehicles as the main means of transportation. All of the respondents showed an interest in the topic. Many believed that the idea is quite nice, but it is not realistic in practice. "Changing the car is an issue and creating electricity is still damaging the environment. Electrics are harder to fix". "I think it should be put on hold, since there are not enough charging points in London and the surrounding areas". One of the respondents suggested that as soon as the electrics are able to compete with $300+\mathrm{m} / \mathrm{ph}$ cars and partial recharge takes 15 minutes it is a good idea to change all the other means of land transport. It is worth saying that all the respondents more or less understood the fact that the electricity is somehow being produced, and if that is generated by coal-powered station, it is not worth a step to take. 
Question 14 was asking the respondents to express their thoughts on the future of the electric vehicles. One of the repondents was obviously too excited with the idea and just answered that the future is very bright. Others answered that they were not sure about the future of electric vehicles while they can be powered by a cleaner source of electricity and they became cheaper or more efficient. "I think we can see more of them in towns and cities but until batteries allow amuch longer range, I don't believe they will replacce petrol or diesel cars." All in all people think that the future holds great possibilities if the technologies develop further. But as to the present moment people think it might not be a good idea to move the emissions from the tailpipe to power stations. The explanation to this type of answer may again be the psychological fact that people usually resist the changes and are not immediately welcoming technological novelties. However, the results for the open questions are satisfying and give a huge base for further discussions but the limitation of time and space is a disadvantage for such type of research which was supposed to be accomplished in 3 months time.

Question 16 was just a feedback and was not a compulsory question. It was just suggesting the respondents to leave their comments there. One of the respondents was attentive enough to mention in this section that the electric vehicles should make noise otherwise the pedestrians will not be aware of their presence. Here the respondent has quite a good point there. The other respondent added, "I believe the combination of traditional engine and electric motor is still the best option until we do not solve the problems connected with the batteries." Another participant mentioned tha the topic for research is quite important, since it will influence her in her future decisions when choosing a car. It is also worth mentioning that the last question was not answered by everyone, and only a small part of the participants spent their time on this one. Out of 39 only 5 people wrote down their concerns and thoughts.

\section{Conclusions}

An Independent Report on the Future of the Automotive Industry (NAIGT, 2009) mentions that in the year of 2008 , there were 1.65 million vehicles and 3 million engines built in the UK. The key point to mention is that the global automotive industry is still growing with the rate of about $2.5 \%$ per year. This is due to the fact of increasing number of car ownerships in the developing economies. As to the UK its automotive industry had a poor reputation based on the quality and productivity issues until recently it recovered itself and transformed into a fully competitive sector.

The importance of the subject was based on such issues as an industrial and environmental problem, important factors for the players of the automotive industry, markets, factors affecting consumers and motor manufacturers, and what can be done to promote the electric vehicles and how to make people choose them over the other types of cars. The aims and objectives were to find out the factors besides of those based on price, which are affecting people's choices when acquiring a new vehicle depending on either it being petrol, diesel, hybrid or electric one.

Thus, the introduction and literature review parts mostly defined the problems and presented the trends for the industry.

By sharing some suggestions from this study, we found that the government might played as an important role, government's strategic decision are also influencing consumers towards purchasing decision making, managers could take advantage of the incentives and policies established by them to better serve their customers according to their needs and wants. Besides, designers should play an important role to consider the price of final products. Although the target customers state that they are concerned about the environmental benefits of green products, they also consider cost as a significant factor which determines their buying decision. Hence, more effort from the businesses organizations are envisaged to disseminate green consumer behaviour among communities. Future research should be conducted to get more generalized understanding of the findings that may receive better acceptance of these relevant findings.

According to Mansor et al. (2014), there are several factors such as environmental benefit, benefit to self, comparative cost, and attainable cost which need to be consider in buying decision process where we would extend for future study. Moreover, we also can focus on purchasing behaviour and comparing types of vehicles consumption with other difference countries.

This study contributes significantly to the development of general automotive industry by emphasized on electric vehicles in future. However, this study was limited by data reliability and the lack of available data. This implies that it is necessary to use other variables such as consumer occupations and other demographic factors related in UK. Furthermore, respondents randomly picked from peoples passing the streets, at the Starbucks and McDonalds. Thus, with the data available to us, our general findings were confined to automotive companies in UK only. Future research should look into this aspect. 


\section{References}

Goodall, C. (2009). The Green Guide for Business: The Ultimate Environment Handbook for Businesses of All Sizes. Profile Books.

Hailes, J. (2007). The New Green Consumer Guide. Simon \& Schuster.

Hansen, F., \& Christensen, S. R. (2007). Emotions, Advertising and consumer choice. Copenhagen Business School Press.

Hoyer, W. D., \& Macinnis, D. J. (2010). Consumer Behaviour (5th ed.). South-Western Cengage Learning.

Macbride, P. (2009). Ethical Living. Emerald Group Publishing.

Mansor, N., Yahaya, S. N., Nizam, N. Z., \& Hoshino, Y. (2014). Consumers' Acceptance towards Green Technology in Automotive Industries in Malacca, Malaysia. International Journal of Business Aministration, 5(1), 27-30.

Mayor and Greater London Authority. (2009). An Electric Vehicles Delivery Plan for London May. Retrieved from https://www.london.gov.uk/sites/default/files/electric-vehicles-plan_1.pdf

New Automotive Innovation and Growth Team (NAIGT). (2009). An Independent Report on the Future of the Automotive Industry in the UK. Retrieved from http://www.berr.gov.uk/files51139.pdf

Nussbaum, D. (2008). Doing Business in the Global Environment: Corporate Social Responsibility as an Organisation's Core Business Strategy. Unpublished paper.

Scurlock, J. (2010). Biomass: Greening the Transport System in Sustainable Energy: Opportunities and Limitations.

Solomon, M., Bamossy, G., Askegaard, S., \& Hogg, M. K. (2006). Consumer Behaviour (3rd ed.). Prentice Hall. http://news.bbc.co.uk/1/hi/7938001.stm; accessed on 09/11/2010

http://www.berr.gov.uk

https://www.london.gov.uk

https://www.sourcelondon.net/source-london

https:www.smmt.co.uk

\section{Appendix A}

\section{Questionnaire Sample}

The following questionnaire is needed for a research and it will help us to evaluate the environmental awareness of people as customers of motor industry and find out what are the factors affecting them in choosing and acquiring a vehicle. Please answer the questions in all sections and do not hesitate to leave any comments regarding the above-mentioned issues.

Date

\section{Section A}

1. What age group do you belong to? (Please tick the appropriate box)

$$
\begin{array}{lll}
18-25 \square & 36-45 \square & 56-65 \square \\
26-35 \square & 46-55 \square & 65+\quad \square
\end{array}
$$

Male $\square$

Female $\square$

2. Are you?

3. Are you?

Full-time employed

$$
\square \quad \text { Self-employed }
$$

$\square$

Unemployed

Student

\section{Section B}

4. Have you got a driving license?

$$
\text { Yes } \square \quad \text { No } \square
$$

5. Do you own a car?

$$
\text { Yes } \square \quad \text { No } \square
$$

If yes, what type of car do you own? $\quad$ Petrol $\square$ Gas $\square \quad$ Diesel $\square$ Hybrid $\square$ Electric $\square$

6. When have you purchased your car?

7. How much did it cost you? 
8. How did you pay for it? Cash $\square \quad$ Loan $\square$

9. How much are you ready to pay for a new car?

Up to $\quad £ 5000$

$£ 5000-10.000$

$£ 10.000-15.000$

$\square$

$£ 15.000-20.000$

$£ 20.000-25.000$

$£ 25.000-30.000$

$£ 30.000+$

10. Please evaluate the following factors as of importance when buying a new car. (Please tick the relevant box: 1 being the least important, 5 being the highest level of importance.)

$\begin{array}{lllll}1 & 2 & 3 & 4 & 5\end{array}$

\section{Design}

Type of the vehicle

Colour

Brand

Fuel efficiency

Size

Environmental impact

$\begin{array}{lllll}\square & \square & \square & \square & \square \\ \square & \square & \square & \square & \square \\ \square & \square & \square & \square & \square \\ \square & \square & \square & \square & \square \\ \square & \square & \square & \square & \square \\ \square & \square & \square & \square & \square \\ \square & \square & \square & \square & \square\end{array}$

11. How exactly would you consider your concern for the environmental issues as related to your carbon footprint in general?

Strongly concerned

Pretty concerned

Moderately concerned

Little concern

No concern

12. What do you know about the Government's measures as related to electric (alternative fuel) vehicles?

13. What is your opinion on the idea of introducing electric vehicles as the main means of transportation?

14. You would acquire an electric vehicle if:

(Please tick more than one if applicable)

- they were cheaper than petrol and/or diesel alternatives

- there was no road fund license to pay

- the emissions were equal to zero

- they were quiet to drive

- they had a better design

- all the other vehicles were banned

- they were more reliable as to technical issues

(long-run journeys, longer running batteries)

- other (please specify)

15. What do you think about the future for the electric vehicles?

16. Your feedback is valued, please feel free to leave any applicable comments within this section.

Thank you very much for your time and consideration.

(Please send the filled in questionnaire to the following address: r4elle@gmail.com

\section{Copyrights}

Copyright for this article is retained by the author(s), with first publication rights granted to the journal.

This is an open-access article distributed under the terms and conditions of the Creative Commons Attribution license (http://creativecommons.org/licenses/by/3.0/). 